\title{
On the absorption of solar radiation by the carbonic acid of our atmosphere
}

\section{Dr. Ernst Lecher}

To cite this article: Dr. Ernst Lecher (1881) On the absorption of solar radiation by the carbonic acid of our atmosphere, Philosophical Magazine Series 5, 11:65, 76-77, DOI: $10.1080 / 14786448108626975$

To link to this article: http://dx.doi.org/10.1080/14786448108626975

曲 Published online: 12 May 2009.

Submit your article to this journal $[\pi$

Џ Article views: 3

Q View related articles $₫$ 
If the conducting shells are destitute of rigidity, and firmly connected with the dielectric, upon each superficial unit of its inner surface the pressure $\frac{p^{2} \mathrm{D}^{2}(1-k)}{8 \pi a^{2}}$ acts, and upon the same of its
outer surface

$$
\frac{p^{2} \mathrm{D}^{2}(1-k)(a+\alpha)^{4}}{8 \pi a^{4} \alpha^{2}} \text {. }
$$

The dilatation of volume effected by these forces, referred to the unit of volume, is

$$
\frac{\Delta v}{v}=\frac{3 p^{2} D^{2}[2 \lambda+2 \mu-k(\lambda+2 \mu)]}{16 \pi \mu(3 \lambda+2 \mu) \alpha^{2}} .
$$

If the dielectric fills in the same manner the space between two coaxial cylindrical surfaces of radii $a$ and $a+\alpha$, to the elastic force $\mathrm{R}_{\mathrm{t}}$ there is added $\frac{k p^{2} a^{2} \mathrm{D}^{2}}{8 \pi r^{2} \alpha^{2}}$, and the pressure-forces

$$
\frac{p^{2} \mathrm{D}^{2}(1-k)}{8 \pi \alpha^{2}} \text { and } \frac{p^{2} \mathrm{D}^{2}(1-k)(a+\alpha)^{2}}{8 \pi a^{2} \alpha^{2}}
$$

act upon the unit of the inner and of the outer surface. The elongation thereby produced of the unit of length of the hollow cylinder is

$$
\frac{\Delta l}{l}=\frac{p^{2} k \lambda \mathrm{D}^{2}}{16 \pi \mu(3 \lambda+2 \mu) \alpha^{2}} .
$$

Therefore, for $\mathrm{D}=\infty, \frac{\Delta v}{v}=3 \frac{\Delta l}{l}$; and for a lower value of $\mathrm{D}$, $\frac{\Delta v}{v}>3 \frac{\Delta l}{l}$. The former case could be approximately realized for glass. Both quantities are independent of $r$, directly proportional to $p^{2}$, inversely to $\alpha^{2}$. According to this, Röntgen's view may be justified, that Quincke's observations form at least no refutation of the explanation of electrical expansion from the ordinary forces of electric action at a distance and elasticity. An ordinary Franklin's plate of the thickness $\alpha$ must then behave (for instance, even in regard to its optical properties) as if it were compressed by the force $\frac{p^{2} D^{2}}{8 \pi \alpha^{2}}$ upon the superficial unit. After this the construction of the general equations for the deformation of a dielectric body by electrification, or of a magnetic body by magnetization, presents no further difficulty.-Kaiserl. Alcad. der Wissensch. in Wien, 1880, no. xxiii., Sitz. math.-naturw. Classe, Nov. 4, 1880.

ON THE ABSORPTION OF SOLAR RADIATION BY THE CARBONIC ACID OF OUR ATMOSPHERE. BY DR. ERNST LECHER.

Experiments having already been made by Magnus and Tyndall, 
according to which a pretty considerable absorbing-power for radiant heat is possessed by carbonic acid, the author has attempted, in the above investigation, to extend those observations, and to apply them to the atmospheric absorption of the solar radiation. This view is at variance with the generally accepted assumption that the aqueous vapour of our atmosphere is the true absorbent of the sun's radiation-an assumption the groundlessness of which the author has demonstrated in another place.

First, the radiation of a gas-lamp provided with a glass cylinder was investigated; and it was found that carbonic acid in a length of

$$
214 \quad 536 \quad 705 \quad 917 \quad 917 \text { millims. }
$$

transmitted

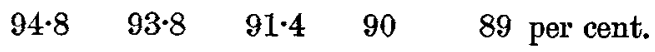

of the incident radiation.

Further experiments (which, for the sake of the pure air, were made out of Vienna, at Greifenstein) show that the solar radiation also suffers a considerable weakening on passing through carbonic acid gas. A layer of this gas of one metre thickness absorbs about 13 per cent. when the sun's altitude is $59^{\circ}$; this number lessens in the same proportion as the sun descends. This proves that the absorption of the solar radiation by carbonic acid is a selective absorption, and that the thicker the atmospheric layer through which the rays have already passed, the scarcer do the absorbable wavelengths become. The author calculates from his experiments the proportion of carbonic acid contained in the atmosphere, and finds it to be $3 \cdot 27$ parts by volume in 10,000 , which number agrees so well with the data given elsewhere, and based upon chemical analysis, that there is the best prospect of determining in this way the carbonic-acid content of the atmosphere, together with its variations and changes, accurately and also at heights where direct measurements are impossible.-Kaiserliche Akademie der Wissenschaften in Wien, Sitz. d. math.-naturw. Classe, Nov. 4, 1880.

\section{SPECTRAL REACTION OF CHLORINE AND BROMINE. BY M. LECOQ DE BOISBAUDRAN.}

When, by the old process, the spectrum of a small bead of chloride of barium is observed in a gas-flame, the lines proper to that compound soon disappear and give place to those of the oxide. Yet for a long time some chlorine remains in the baryta thus heated; the destruction of the $\mathrm{BaCl}_{2}$ is only completed after its volatilization. So, on drawing the induction-spark upon the small calcined mass, the nebulous lines proper to $\mathrm{BaCl}_{2}$ are very distinctly seen, as well as the narrow barium-lines. 